\title{
AN UNIQUE ALMANAC IN THE CODEX MADRID A MISTAKOLOGICAL STUDY
}

Peter JONGEL

Tübingen University

Dedicated to FLOYD LounSBURY, who taught us to take mistakes more serious, in occasion of his arrival to his 5th Katun

The study of mistakes in Maya and, with certain evidence as well, in Mixtec and Nahua written sources, has entered a new stage when F. Lounsbury's study "A Palenque King and the Planet Jupiter" (1989: 246-259, esp. 246-248) appeared by opening a new subfield of Mayanist and Mexicanist research, which I've named "mistakology" in private use. Before, mistakes were recognized and just corrected as "writer's errors", since, it is obvious that mistakes - often, if not ever- are intended and meaningful and their ideas have to be analysed. Evidence for this is accumulating, and this especially from the study of Codex Madrid (CM) (Jüngel, 1991 \& 1992), where countless mistakes are what has lead Mayanists to underrate the reliability of this document.

The most convincing results after Lounsbury have been achieved in $C M$ 75-76 (cartouche of the day-singns and at the trecenas), $C M$ 52b53b (first mistake [of 4], CM 10b-13b (misspelling of T(III).563: 130 used for ordering the pentad of Chacs) and $C M$ 63a, and this just only form the CM. Other exampleshabe been found e.g. in Codex Dresden $10 \mathrm{c}-11 \mathrm{c}$, giving access to an interpretation as a series of numeral regents and Codex Nuttall 22 (Barthel, pers. comm., cited in: Jüngel, 1992: 68 \& 88-89).

This prooves that the mistakes often are no writer's errors but a means of coding/writing and that they are planned as "intended mistakes" (in German: "intendierte Fehler" [iF]). These results proove further that their correction may turn to primary meaning what has been 
intended to be secondary now, and what may have been the invention of an earlier author. A later editor made the mistakes for changing priorities or addition of written message. ${ }^{1}$

The best results in the study of mistakes have been achieved whenever there are more than one mistake in an almanac or chapter. ${ }^{2}$

Such an almanac with more than one mistake is $C M 29 \mathrm{~d}$, which has a truely unique column of day-sings for a $5 \times 52^{\mathrm{d}}$-almanac at its begin. There are 5 different day-signs, which is typical for a $5-52^{\mathrm{d}}$-almanac, and the sum of DN's, though with a mistake (I'll return to this later), accords to this $52^{\mathrm{d}}$-scheme (figure 1 ).

The first day 1 men ( 1 eagle) is followed correctly and at the correct place by 1 manik ( 1 deer). But this latter is succeded by a strange sign which I read as an inverted ben (read) on which ik (wind) supersedes, an unique case in the $C M$ or elsewhere as far as I'm aware. Here the writer seems to have corrected himself. ${ }^{3}$ But the correction is wrong as well (!). Then the wrong day-sing eb (grass/twisted one) is following and at last the correct chuen (monkey), but at fifth instead of foruth position. The correct sequence should be men-manik-cauac (rain)chuen-akbal (house) according to the $5 \times 52^{\mathrm{d}}$-scheme. The mistakes change this scheme into a defective countdown:

$\begin{array}{lc}\text { men } & \text { day-sign } \\ \text { manik (ix) } & 15 \\ \text { ben (with ik) } & 7(14) \\ \text { eb } & 13 \text { (with 2) } \\ \text { chuen } & 12 \\ \text { (1) } & 11\end{array}$

Before I'll discuss the calendrical implications of these mistakes I want to describe the further outlook of the chapter. As the reckonings will be discussed in the forthrun, we can restrict on the picture (figure 1).

${ }^{1}$ The discussion of the role of iF's in the written and possibly artistic sources as well and its significance for understanding Mesoamerican writing systems, has only begun (Jüngel, 1992:150 \& 64), but here I don't want to go into details.

2 "Miscalculations", wrongly written numbers (or true writer's errors), have yet withstood most attempts of interpretation. The most convincing exceptions are $C D 10 \mathrm{c}-$ 11c (Barthel, 1968: 76-81). That may depend on the rate of yet known operating methods of calendarical mistakes and their ideas represente. We've just begun their study.

${ }^{3}$ There is a further self-correction in CM $109 \mathrm{c}-110 \mathrm{c}$, that, can't be compared to this one and which is basic for the understanding of the organization of the $C M$ (Jüngel, 1992: 55-56). 


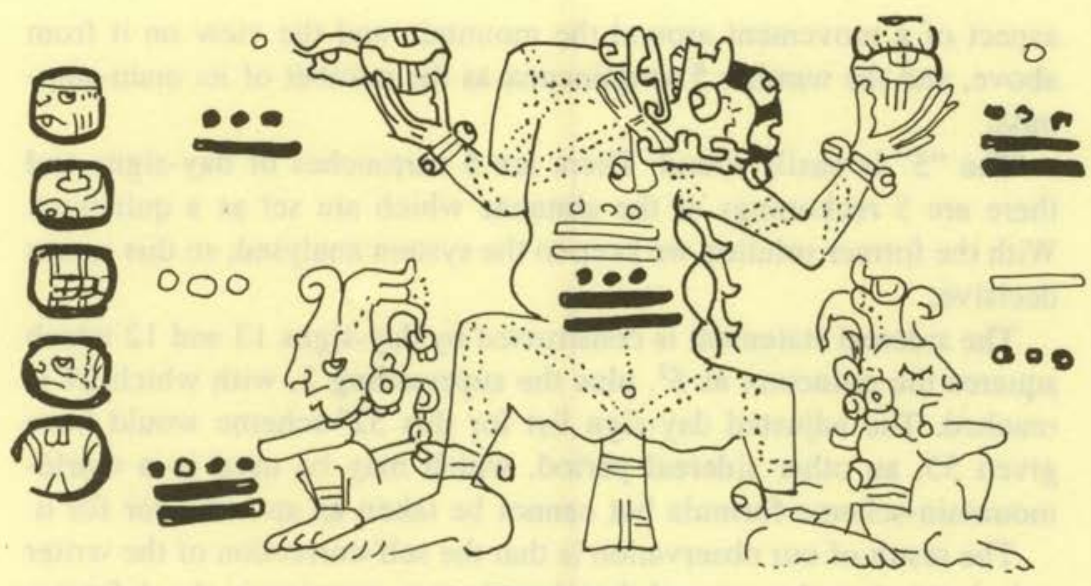

Figure 1

It shows God A in the position HAW (volver algo boca arriba; Cordemex, 1980: 186-187) standing with T506 in his hands and two Gods E sitting on his feet. There is no accompanying glyphic text. Let us turn to some ideas connected with the set of day-sings chosen before we discuss the calendarical implications. The later calendarical observations do not depend on the day-signs efectively used ${ }^{4}$-and an explanation for the start day cannot be given from the almanacs CM 29b and $7 \mathrm{~b}$ which are somehow related to $C M 29 \mathrm{~d}$.

The day-sign list men-manik-ben/ik-eb-chuen can be subdivided into two classes, one of day-signs belonging to the $52^{\mathrm{d}}$-scheme and the other of those who don't.

The day-signs 15 and 7 form a first, and day-sign 11 a second subgroup in the former class, because day-sign 11 is at the wrong place.

The numerical equivalents of the day-signs of the first class form a 2:1-division. The sum of the first subgroup is 22, that of the other is 11 . The whole class has the sum 33. Barthel (pers. comm.) and Jüngel (1992: 105-137 \& elsewhere) interprete "33" as a numerical device for the description of a "world-mountain" ("Weltberg") from its profile, especially when " 33 " can't be analysed in the classical Mexican manner as $20+13$ and the case here. This isn't if this is true here, according to Barthel (pers. comm.), we must expect to find a statemente on sidereal months, 109 or one of its constituents, i.e. $27,28,54,55$ or 82 , as

${ }^{4}$ Maize and maize-products are thus avoiding the endangerment of a passage of God A in a secondary interpretation of God's A role in this almanac. 
aspect of a movement around the mountain and the view on it from above, and the number 5 or quincunx as the number of its main-summits.

The " 5 " is easily found: There are 5 cartouches of day-signs and there are 5 reckonings of the almanac which are set as a quincunx. With the former solution we keep to the system analysed, so this seems decisive.

The sidereal statement is constructed by day-signs 13 and 12 which squares the quincunx as $5^{2}$, plus the superseding 2 , with which 27 is reached. The adjusted day-sign list for this $52^{\mathrm{d}}$-scheme would have given 55, an other sidereal period, which may be used in a worldmountain-scheme-formula but cannot be taken as an indicator for it.

The result of our observation is that the self-correction of the writer only pretends to be one and that there is true meaning in the defective column of the day-signs so that we can suppose that there is fruther one in the calendarical context.

Our analysis adds a further example to those of the "world-ountainscheme" Quincunx-Profile-Sideral which I have found elsewhere in the CM (Jüngel, 1992) adding a further likely characterization to one of its main-summits, here the summits inhabited by the deathgod. This concept is also known especially from southern Veracruzan and Pueblan sources spanning more than 1000 years of continual observability (Barthel, pers. comm.).

Because of the lack of a glyphic text in $C M 29 \mathrm{~d}$ we habe to try to get any bits of intended meaning from the column of the day-signs if we don't want to transfer the text of the somehow related $C M 29 \mathrm{~b}$ on this one. The other related almanac $C M 7 \mathrm{~b}$ has no text either. The results of the further study of the day-signs will add to the understanding of the world-mountain-concept here.

In the centre of the column (M. 29d) is the if it is ik-supersedingben-compound. In its centre-position it is matched by that of the deathgod with the reckonings set in form of a quincunx in the picture. A reading of the ben-ik-conflation as "ah ik", "he or master of life" (Kurbjuhn, 1989: 63 sub T503 \& 79 syb T584), makes us aware of the antithesis to the deathgod in the picture.

The ben-ik-conflation is preceded by manik in the column. If chimanik is spoken as "man ik" or "ma(n) ik" it can be understood as "buying of life" in the former (Cordemex, 1980: 493 man) or as "no life" (ibidem: $469 \mathrm{ma}$ ) in the latter case, both reflecting in one way or the other a deathgods role which adds to some sort of (reciprocal?) re- 
lations of death and life. The role of the relations of death and life are in accordance to the concept of a world-mountain, as the same coexistence and relationship is found in CM 75-76 (Jüngel, 1992: 105-137).

I think that the ideas expressed by the day-signs are clear enough though incomplete. It is an other matter, however, whether we are allowed to use the results of $C M 29 \mathrm{~d}$ in a change of paradigma for the realted almanacs $C M$ 29B and 7b. I don't want to attempt it here, being still unsure on the suitability of such a change.

Now I'll turn to the discussion of my main concern, the discussion of the calendarical parts of $C M 29 \mathrm{~b}$.

Besides the mistakes with the day-signs there are three more mistakes in the reckonings of the almanac. The DNs fall 1 day short of the correct 52 days needed and two day-numbers are wrong. This is the reason why neither Förstemann (1902: 50-51) nor Villacorta \& Villacorta (1930: 282) nor Evreinov et al. (1961: 99) have described the scheme of calculation. My proposal is:

\begin{tabular}{|c|c|c|c|c|c|}
\hline 1 men & - manik & - cauac & - chuen & - akbal & +14 \\
\hline [2] muluc & - imix & - ben & - chicchan & - caban & +3 \\
\hline $5 \mathrm{eb}$ & - kan & $-c i b$ & - lamat & - ahau & $+[9]$ \\
\hline 1 imix & - ben & - chicchan & - caban & - muluc & +13 \\
\hline $1 \mathrm{ix}$ & - cimi & - edznab & $-o c$ & $-i k$ & +13 \\
\hline
\end{tabular}

The third reckoning has a secondary alternative in the first run which takes its intended mistake up to the finish of this run:

$5 \mathrm{eb}$

[13] ahau

[13] ben
$+8[13]$ ahau

$+13[13]$ ben

$+1313 \mathrm{cimi}$

\section{Comment:}

The start of the reckonings is in the lower left corner at God's A right foot. The calculations end in the centre where they often seem to end when they are set in form of a quincunx. [Not qu te. D3a begins in the centre].

The sequence of the reckonings and their placement in $C M 29 \mathrm{~b}$ probably forms the same scheme as that of the related CM $29 \mathrm{~b}$ (see appendix 1, left alternative). In $C M 29 \mathrm{~d}$ the sequence seems to describe the 
life cycle of maize. At God's A two feet, the first two stations, the maize isn't harvested yet and is represented by two Gods E with slightly different eyes and God's A hands the maize is harvested and in different states of preparation which is represented by T506 and its different affixes. The fifth calculation, a downward movement, may represent the sowing, the symbolical death and interment of maize because God A is the god of the underworld and in his body are written these last two numbers.

The alternative reckonings in the first run introduce a name or title for God A, 13 cimi (13 death), into the series, especially as this is written on his body, and those of his counterpart/conterparts 13 ahau (13 lord) and 13 ben. If 13 ben is read as $13 a^{5}$ (Kurbjuhn, 1989: 79 sub T584) the same 13 lords or 13 Lord may be named. This takes up the life death-opposition already recognized in the column of the day-signs.

Not fully clear to me is the mistake of day-number 2 written as 3 . Either $3 \mathrm{oc}$ is meant to be an approximation of the positive attributive glyph TIII.563.130 or it is an augury of "a good amount of water" as "3 water" is the day after $2 \mathrm{oc}$ and that is cited instead of $2 \mathrm{oc}$. A third possibility might be searched for in the context of a solar year.

The scheme of reckonings described doesn't run through the whole tzolkin if we consider $(/)$ the incompleteness of the day-sign list as meaningful. There is indicated a change of paradigma for the mode of calculation according to the column of the day-sign after 1 manik - and its predecessor 13 days earlier, i.e. $1 \mathrm{ix} .1 \mathrm{ix}$ could be "expected" as second place in the count-down of the day-signs. Obviously the fifth addition is allowed to be dropped or ignored, ${ }^{6}$ transforming the almanac into a triple-tzolkin of $20 \times 39^{\mathrm{d}}$ which matches the count-down: ${ }^{7}$

$\begin{array}{llllll}1 \text { men } & -\mathrm{ix} & - \text { ben } & - \text { eb } & - \text { chuen } & +14 \\ \text { [2] muluc } & - \text { lamat } & - \text { manik } & - \text { cimi } & - \text { chicchan } & +3 \\ 5 \mathrm{eb} & - \text { chuen } & - \text { oc } & - \text { muluc } & - \text { lamat } & +[9] \\ 1 \mathrm{imix} & - \text { ahau } & - \text { cauac } & - \text { edznab } & - \text { caban } & +13 \\ 1 \mathrm{ix} & - \text { ben } & -e b & - \text { chuen } & -[\text { oc }] & \end{array}$

Only a fourth of this triple-tzolkin is attested if we consider 1 chuen as the start for a further run and not as its final day. Otherwise only a fifth is stated.

${ }^{5}$ Previously Lounsbury.

${ }^{6}$ The $39^{d}$-stations are marked as far as the calendar is supposed to go with certainty.

${ }^{7}$ See note 6. 
Such triple-tzolkins are known from Codex Dresden $44 \mathrm{~b}-45 \mathrm{~b}$ and its counterparts $C M$ 1a-2a and $1 \mathrm{~b}-2 \mathrm{~b}$ and from $C M$ 26b-27b, the latter one matching this one in its $20 \times 39^{\mathrm{d}}$-structure. It has been observed that the $C M$ examples are neighbours to the only two almanacs of burner-ceremonies found in the $C M$ (Jüngel, 1992: 7). The triple-tzolkin of $C M$ $29 \mathrm{~d}$ doesn't follow this scheme though a $4 \times 65^{\mathrm{d}}$-almanac is integrated into $C M 29 \mathrm{~d}$ as well (see below) which is the typical calculation-mode of those almanacs.

The integration of one style of almanac-structure into an other one, which runs independently and parellel to the former and expanding the original one, hasn't been observed yet with certainty in Mayan documents. The incompleteness of the day-sign list for this other scheme depends on the primacy of the $5 \times 52^{\mathrm{d}}$-structure and may be unique. But it is no real obstruction. The count-down can be completed very easily from memory.

In the column of the day-signs are three of four day-signs necessary for a $4 \times 65^{\mathrm{d}}$-almanac, i.e. day-signs manik, ik and eb, leaving caban as the only missing. These three are the central ones in the column. Their sequence is corrupt for ik should precede manik or follow after the dropped caban. In each case, the $4 \times 65^{\mathrm{d}}$-structure demands a different basis-day, either $1 \mathrm{ik}$ or $1 \mathrm{manik}$, than the $5 \times 52^{\mathrm{d}}$-almanac.

A reconstruction of a $4 \times 65^{d}$ scheme leading to a solution leaving not too much room for alternatives would be one which includes the $5 \times 52^{\mathrm{d}}$ - and the $20 \times 39^{\mathrm{d}}$-schemes and a $10 \times 26^{\mathrm{d}}$-scheme not yet taken into consideration. This latter one is only attested by day-signs manik and ben as such which doesn't seem to b sufficient for proposing it.

\section{Comment:}

The sequence from 1 manik to 1 cauac might be different:

$$
1 \text { manik }+13=1 \text { ahau }+13=1 \text { ben }+14=[2] \text { manik }
$$

[2] manik $+3=5$ oc $+[9]=1$ cauac

The sequence of the steps of calculation must change to fit this scheme. It can't yet be decided whether the sequence of the second $52^{\mathrm{d}}$-series is following that of the first or that of the third scheme. It is, however, important that this change is happening at all. This could allow different versions of schemes whenever there are provisional results which are multiples of DN 13 which are different from that of the scheme of the almanac. 


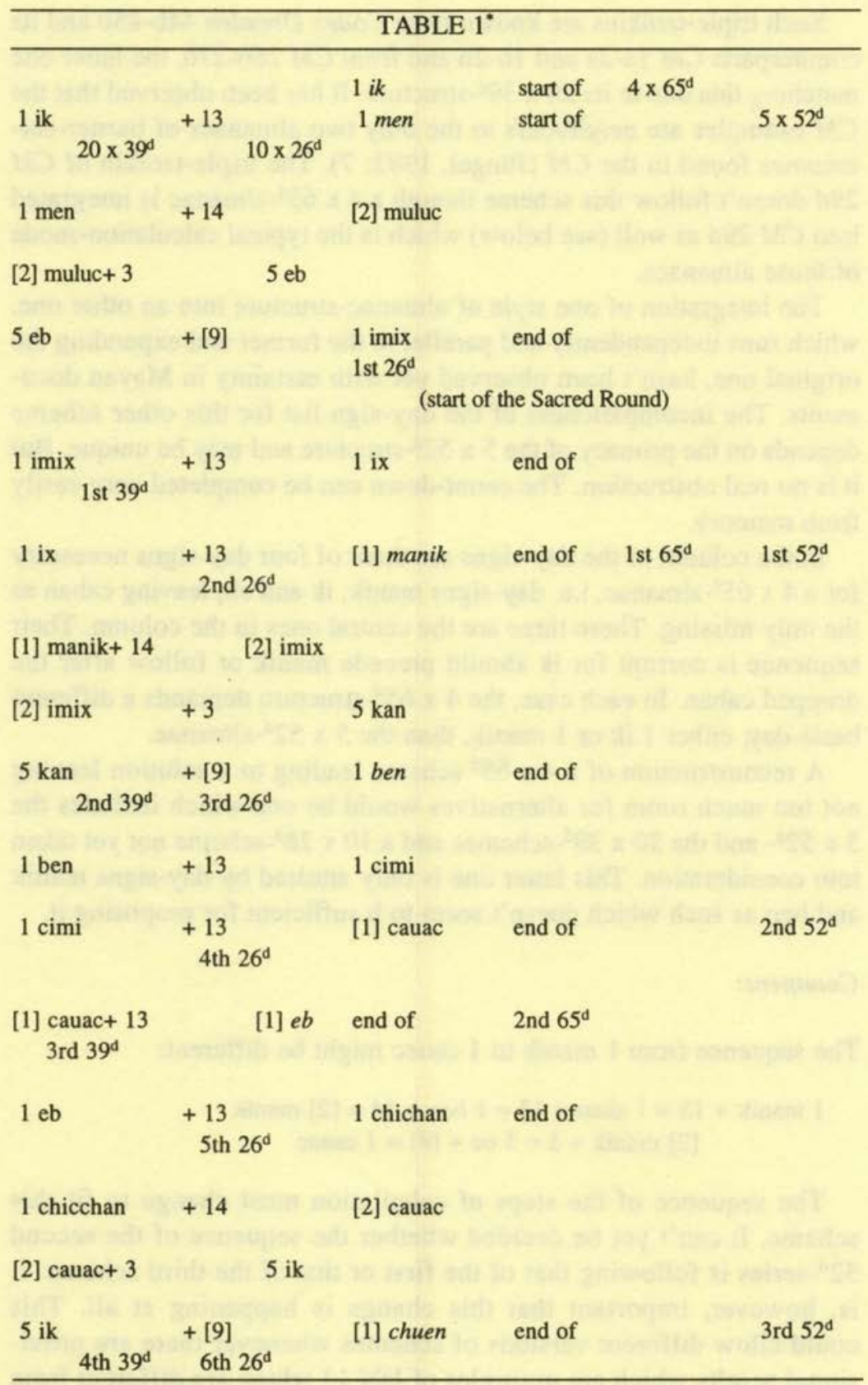

- The day-signs stated in the column are marked. 
This last scheme for the calendarics seems to be the invention of a later editor rewriting the original $5 \times 52^{\mathrm{d}}$-scheme. The integration of the $4 \times 65^{\mathrm{d}}$-scheme seems to have happened still later than that of the $20 \times 39^{\mathrm{d}}$-scheme though the reasons for integrating the latter aren't yet understood apart from their calendarical purposes. The earlier state of rewriting has to be concluded from the fact that day-sign ben was written earlier than day-sign ik. There is no need to suppose such a highly organized form for the integration-process of the $20 \times 39^{\mathrm{d}}-$ scheme as it seems necessary for the still later one. We have to take into further consideration that the ideological concept needn't be the reason for the rewriting of $C M 29^{\mathrm{d}}$ right from the start though it seems to be the only overall important reason to do this. This concept is surely one major if not the only reason for the final state of $C M 29^{d}$. In it the earlier one or two versions are taken up, incorporated and modified.

If my observations and the conclusions concerning the calendarics are correct we've got to know a bit of the Maya priests' mastership in the manipulation of the tzolkin, adding to our ethnographic data on this matter.

Such a case of more-level-organization of different schemes of tzolkin-divisions into one almanac hasn't been observed in Maya written sources. I know of only one comparable proposal, though, the integrated series is of astronomical instead of calendarical nature. Barthel (1968: 47-52) proposed for Codex Dresden (CD) 4a-10a that an unexpressed DN $52^{\mathrm{d}}$ should be added to each of the 20 DNs there so that each step would represent, more or less precise, multiples of two sideral months. The $5 \times 52^{\mathrm{d}}$ structure was thus expanded to $1092^{\mathrm{d}}$ (and, to meet a full-numbered multiple of the tzolkin, Barthel doesn't discusses this possibility, to 21 tzolkins or $5460^{\mathrm{d}}$, where the error would have accumulated to 4.33 days).

Barhtel's considerations were dependent on the observation that $C D 4 \mathrm{~b}-5 \mathrm{~b}$ has the same introductory glyph including $\mathrm{T} 759$, the portrait of the lunar animal, the rabbit, as main-sign as $C D$ 4a-10a, expanding the number of pictured or named gods to 27 , which is a fullnumbered approximation of one sidereal month (Aveni, 1980: 100) by adding 7 gods. These 7 gods are repetitiones of those of $C D 4 a-10 a$.

Viewed from $C M$ 29d, hints for such an alternative scheme of reckoning is scarce in $C D 4 \mathrm{a}-10 \mathrm{a}$ itself. If there are no more direct allusions expressed in an other form, one has to judge Barthel's considerations as yet still ill-founded so far. 
An integration of periods of astronomical observations and rites into a quarter-division of the tzolkin has been reported for the recent Momostenango-Quiché (B. Tedlock, 1990: 425-428). Tedlock observed a ritual cycle of $4 \times 65^{\mathrm{d}}$ to which a cycle of 4 overlapping periods of $82^{\mathrm{d}}$ or 3 sidereal months is running parallel from bases of the $65^{\mathrm{d}}$-count. Every $82^{\mathrm{d}}$-period is started by opening a mountain-shrine in one of the four cardinal points and is ended with its closing. Every shrine is shut down for $178^{\mathrm{d}}$ which are 6 synodical months. The opening period of two consecutive shrines is $147^{\mathrm{d}}$ or 5 synodical months and, further, the second shrine will be reopened for the second time $325^{\mathrm{d}}$ or $5 \times 65^{\mathrm{d}}$ after the first opening of its predecessor, $325^{\mathrm{d}}$ are 11 synodical months as well.

These mechanisms allow reckonings of the sidereal and the synodical movements of the moon in the context of a tzolkin and describe the changing relations between them. The results of Tedlock's research demonstrate that the Maya used and still use to operate with periods of time of differente lengths and nature in a highly organized form. Tedlock's observations do this for a division of the tzolkin and astronomical cycles, $C M 29 \mathrm{~d}$ does the same with different divisions of the tzolkin keeping to calendarical time in origin and nature.

There is some, but not wholly conclusive evidence that Tedlock's observations may be represented in $C M 29 \mathrm{~d}$ as well: The first $65^{\mathrm{d}}$-period of table 1 starts with a $27^{\mathrm{d}}$-period, i.e. a full-numbered representative of one sidereal month. This is expanded by $3^{\mathrm{d}}$ to $30^{\mathrm{d}}$ or 1 synodical month. Further, this first $65^{\mathrm{d}}$-period can be expanded to $82^{\mathrm{d}}$. More over, the day-name ik of its basis is one of those used in the $65^{\mathrm{d}}-82^{\mathrm{d}}$-scheme in the Quiché-scheme though the day-number is 9 instead of 1 in the Quiché-scheme and there, a $3^{\mathrm{d}}$-period is, but only, at the end of the $82^{\mathrm{d}}$, lasts the closing-ceremony for the mountainshrines in Quichean Momostenango (B. Tedlock, 1990: 426).

The parallels are quite striking and could be still more when we consider a $4 \times 65^{\mathrm{d}}$-scheme running independently from the other schemes and that is rearranged to fit completely the Quiché-mode. The sequence of sums would be about:

$$
14+3+9+13+13+13\left(65^{\mathrm{d}} \text {-station }\right)+14+3
$$

In that case we have to suppose that one addition of $13^{\mathrm{d}}$, likely that of the centre, is repeated once every $65^{\mathrm{d}}$-period and we have to give up the idea of a $27^{\mathrm{d}}$ - and a $30^{\mathrm{d}}$-period at the start. But now we would 
have included the time of the Quichean closing ceremony and all the other astronomical sizes of the Quiché example.

Though parallels are so striking and though we are entitled to construct an independent $4 \times 65^{\mathrm{d}}$-scheme, this in analogy to that of the $20 \times 39^{d}$-scheme. Such a proposal doesn't seem to be appropiate because certain evidence for an astronomical matter in CM 29d is missing. There are no eclipse-glyphs or skybands. The obstruction is true though God's A "HAW"-position, his looking upwards (to the sky? in a dancing-pose?), may plead for such an interpretation.

The analysis of mistakes in $C M 29 \mathrm{~d}$ gives access to a partition in a certain ideological concept and to an arranging of different tzolkin-divisions into a highly organized form which hasn't been recognized with certainty in Mayan codices before. The latter is met in principle by a recent calendarical practice and makes us known a bit of the Maya priests' mastership in using the operation modes of their calendars.

\section{APPENDIX 1 \\ THE SCHEME OF CALCULATION OF CM 29B}

The $5 \times 52^{\mathrm{d}}$-almanac CM 29b hasn't been understood and described yet by earlier scholars. The cause is a misreading of one day-number caused by the quality of earlier editions of the codex. But scholars can stay away from accepting the too obvious only by a very close look on the critical place. It's a "day-number" 1 which is written much too big and in a shade of colour much too dark in comparison to others on this and accompanying pages. A " 5 " is leaving to the right from this point (figure 2), the rest has faded nearly completely. This corrected reading allows the description of the scheme in which I will omit the daynames:

$\begin{array}{cccccc}1 \ldots & +[10] & =11 \ldots & \text { or } 1 \ldots & +17 & =5 \ldots \\ 11 \ldots & +7 & =5 \ldots & & \\ & 5 \ldots & +9 & =1 \ldots & \\ 1 \ldots & +17 & =5 \ldots & \text { or } 1 \ldots & +[10] & =11 \ldots \\ & & & 11 \ldots & +7 & =5 \ldots\end{array}$




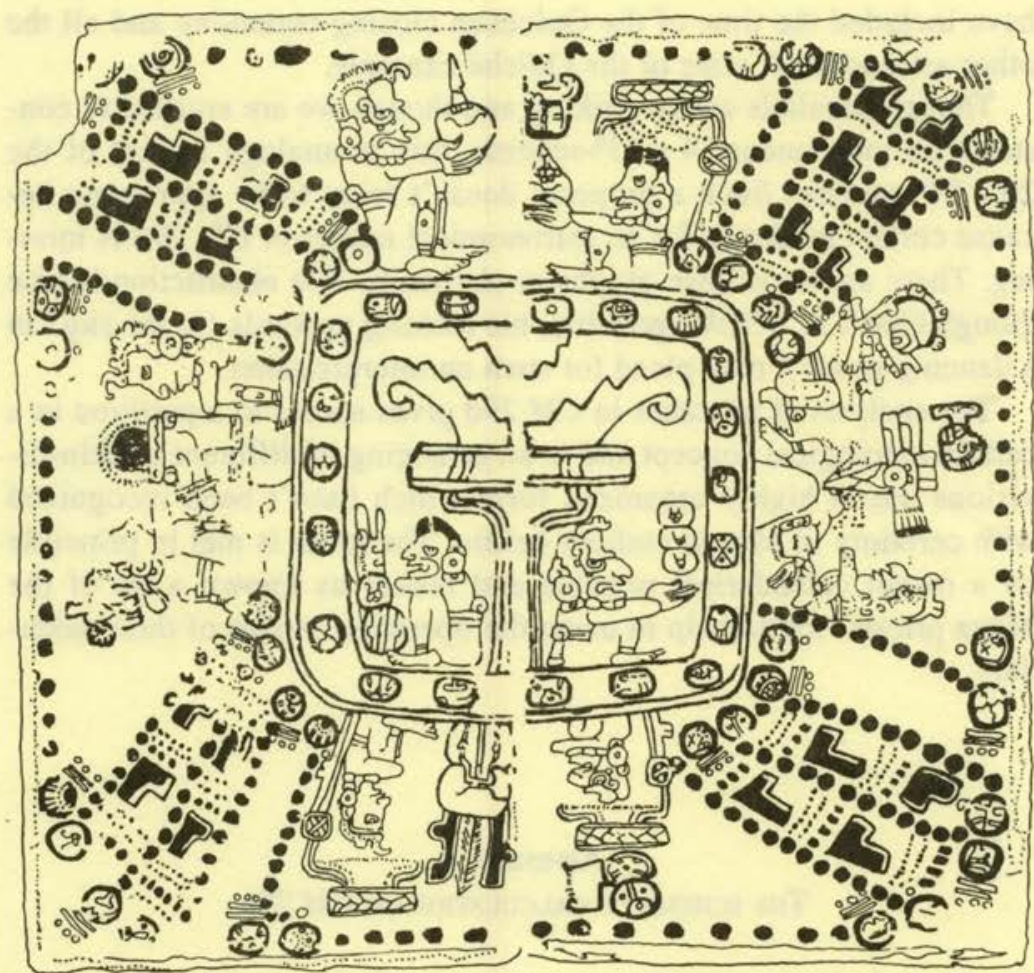

Figure 2

Because there are two partial sums forming multiples of 13 there are two alternatives for the sequence. I've not found any hints which would give a preference for one or the other.

APPENDIX 2

Mistakological STUdies AND THE ZEITGEIST

The new attitude towards mistakes in Mesoamerican sources is surely a result of a certain feature of the zeitgeist. So it isn't surprising that scientific solutions which could have been achieved decennia earlier are found today. A look in our streets with their graffitis on the walls offers us our daily experience of mistakes with allusions only made possible by the mistakes. This mistaken messages have returned to our minds in the 60 s or still later when they got popular again. So our time 
is open to the experience of "intended mistakes". This prooves the time-boundedness and modernity of "mistakological" studies for the study of Mesoamerican cultures.

\section{Bibliography}

AvenI, Anthony F.

1980 Skywatchers of Ancient Mexico. Austin \& London.

BARTHEL, Thomas S.

1968 "Götter-Sterne-Pyramiden-Ein Beitrag zur strukturellen Mayaforschung", Paideuma, 14: 43-92. Frankfurt/Main.

Codex MADRID

1967 Codex Tro-Cortesianus (Codex Madrid), Museo de América, Codices-Selecti-Series VIII, Graz.

CORDEMEX

1980 Diccionario Maya Cordemex: Maya-Español, Español-Maya, Ediciones Cordemex (vol. ed.: Alfredo Barrera Vásquez), Merida.

Evreinov, E. V., Y. G. Kosarev \& V. A. Ustinov (= Evreinov et al.),

1961 "Primenenie elektronnikh vichislitelnikh mashin $\mathrm{v}$ issledovanii pismennosti drevnik Maya", vol. I, Novosibirsk.

FöRSTEMANN, Ernst W.

1902 Comentar zur Madrider Mayahandschrift (Codex Tro-Cortesianus), Danzig.

JÚngel, Peter

1991 "Mistakes and "Mistakes": to the Ambivalence of Mistakes - a Proof of Theses". Estudios de Cultura Maya XVIII: 339-358. Mexico.

1992 Ein yukatekisches Buch des Rates-Stand, Probleme und Perspektiven der Erfoschung der Mayahandschrift Codex Madrid, doctoral thesis, Tübingen.

LOUNSBURY, Floyd G.

1989 A Palenque king and the planet Jupiter. In: World Archaeoastronomy - selected papers from the 2nd Oxford International Conference on Archaeoastronomy held at Mérida, Yucatan, Mexico (1986), ed. by Anthony F. Aveni, Cambridge University Press, Cambridge, New York, New Rochelle, Melbourne, Sydney, pp. 246-259. 


\section{TEDLOCK, Barbara}

1990 "Die innere Verhältnismäßigkeit in der Astronomie und im Kalenderwesen der Maya-Quicé”, in: Circumpacifica Festschrift für Thomas $S$. Barthel, vol. I., pp. 415-435, ed. by Bruno Illius \& Matthias Laubscher, Frankfurt/Main, Bern, New York, Paris.

Villacorta C., J. Antonio, \& Carlos A. Villacorta,

1930 Códices mayas reproducidos y desarrollados, Tipografía Nacional, Guatemala. 